This item was submitted to Loughborough's Research Repository by the author.

Items in Figshare are protected by copyright, with all rights reserved, unless otherwise indicated.

\title{
3D printing, inkjet printing and embroidery techniques for wearable antennas
}

PLEASE CITE THE PUBLISHED VERSION

http://dx.doi.org/10.1109/EuCAP.2016.7481266

PUBLISHER

(c) IEEE

VERSION

AM (Accepted Manuscript)

LICENCE

CC BY-NC-ND 4.0

REPOSITORY RECORD

Whittow, W.G.. 2019. "3D Printing, Inkjet Printing and Embroidery Techniques for Wearable Antennas". figshare. https://hdl.handle.net/2134/23776. 


\title{
3D Printing, Inkjet Printing and Embroidery Techniques for Wearable Antennas
}

\author{
William G Whittow ${ }^{1}$ \\ ${ }^{1}$ Wolfson School of Engineering, Loughborough University, UK, w.g.whittow@lboro.ac.uk
}

\begin{abstract}
This paper will review techniques of manufacturing wearable antennas. 3D printing can be used to create flexible substrates. $3 \mathrm{D}$ shapes can be created which can be used to reduce the antenna size. Embroidery will also be discussed. The technique naturally lends itself to linear antennas.
\end{abstract}

Index Terms — wearable antennas, 3D printing, embroidered antennas.

\section{INTRODUCTION}

The world is becoming increasingly reliant on wireless communication. Some widely quoted statistics and estimates of the future proliferation of this technology include: i) there will be 50 billion devices connected to the internet by 2020 [1]; ii) we now create more data in less than 10 minutes than we did in all of human history up until 2008 [2]; iii) there will be close to a trillion sensors in 5 years and approaching 100 trillion sensors by 2040 [3] - this corresponds to approximately 10,000 per person. Note, different sources have different numbers and any predictions of the future have uncertainties. Many of these devices will require wireless connectivity. Wearable antennas have been discussed for many years [4]. However, it is only with the recent miniaturization of computing and development of the associated electronics that are driving the current growth in wearable technology. There are hundreds of millions of wearable devices that are shipped every years and this is universally predicted to keep growing. The markets include sport and leisure, military, health, wellbeing and the medical sector (however the administrative obstacles to entry are larger). The possibilities are limited only by the public imagination, for example CuteCircuit have already developed a dress that has an inbuilt Twitter feed. The technical advancements and commercial opportunities need to be marketed in the right way to capture the public's interest. Smart glasses [5] have had limited success thus far but are likely to reworked in the near future. Smart watches are currently popular with an aesthetic form and convenient user interface. It is likely that the next generation of smart wearable technology will be embedded directly into the clothing and the associated sensors will perform intelligent functions without the user being aware of their presence.

All of these emerging technologies will require smaller antennas or antennas that can be embedded into conformal or flexible shapes and materials. Interesting work on wearable antennas includes but is by no means limited to [6]-[17]. It is well understood that the body is not the ideal place for an antenna. The relative permittivity of the body can detune the antenna and the lossy material can reduce the efficiency. A small separation can mitigate these effects to some extent. The effects are more severe at low frequencies where the wavelengths are larger. The tissue type and composition is important. At $1.8 \mathrm{GHz}$, muscle has a relative permittivity of 53.55 and a conductivity of $1.34 \mathrm{~S} / \mathrm{m}$, while the same properties of fat are 5.35 and $0.08 \mathrm{~S} / \mathrm{m}$ [18]. The effects of the body are smaller when there is a high fat content. Fortunately for antenna engineers, the world is suffering from an obesity epidemic. It is therefore ironically appropriate that some wearable technology will be used for health conditions brought on by obesity.

\section{3D PRINTING}

3D printing, see Fig. 1, is an exciting discipline that is highly topical with applications in many fields. The process allows bespoke shapes to be created with geometries that would be impossible using conventional machining. Furthermore, by varying the internal structure, we can alter the dielectric properties. If air inclusions are added inside a host material the relative permittivity is reduced [19]. If metallic or high permittivity inclusions are added in a matrix, then the permittivity can be increased [20], [21].

3D Printing has a rapidly expanding palette of materials. They have thus far been largely designed for their physical properties and can be highly flexible, see Fig. 2. The dielectric properties of the 3D Printed samples were measured using a split post dielectric resonator at $2.4 \mathrm{GHz}$, see Fig. 3 [22]. The measured results are shown in Table 1.

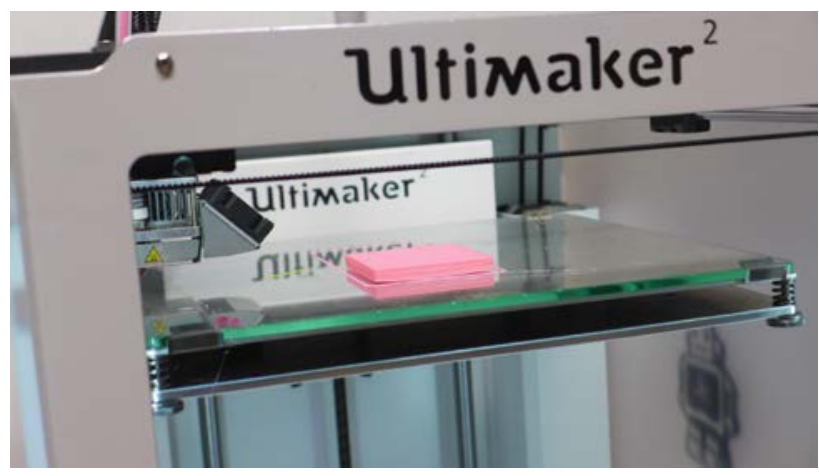

Fig. 1. One of several 3D Printers at Loughborough University 


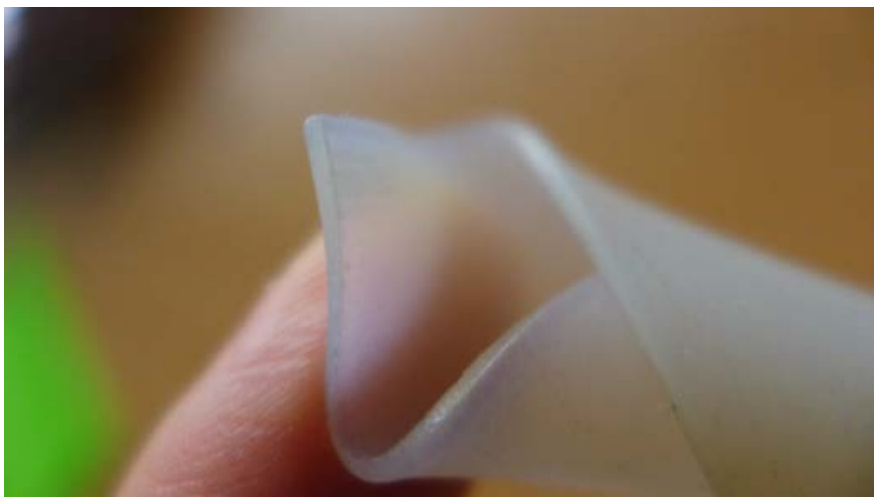

Fig. 2. DM9760 is a flexible 3D Printed Material

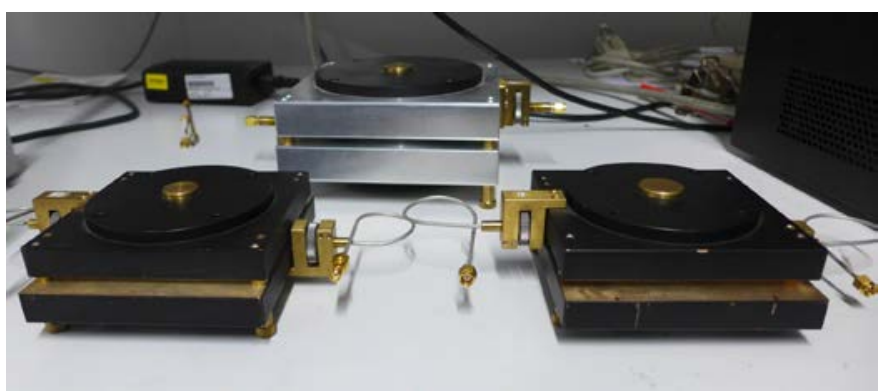

Fig. 3. Split post dielectric resonators at 1.1, 1.9 and $2.4 \mathrm{GHz}$

Table 1. Measured dielectric properties of 3D Printed samples

\begin{tabular}{|c|c|c|}
\hline & $\varepsilon_{\mathrm{r}}$ & $\tan \delta$ \\
\hline Vero White & 2.98 & 0.029 \\
\hline DM8425 & 3.01 & 0.032 \\
\hline DM9760 & 2.99 & 0.051 \\
\hline
\end{tabular}

3D Printing is gathering significant interest in terms of its potential for electromagnetic applications [23], [24]. Alternative materials have lower loss tangents at microwave frequencies. Recent developments allow composite mixtures with enhances permittivity or permeability to be made and then extruded and printed or cast [25].

3D Printing allows the shape to be altered so that antenna designers are no longer constrained to flat substrates. Underneath a patch antenna the electric fields are not uniform and hence there is scope for extra degrees of freedom by changing the geometry. For examples ridges can be added to the center of the patch antenna, see examples in Fig. 4. Note metal tape was added for the ground and patch. The results for a triangular and curved ridge are shown in Fig. 5. Empire finite-difference time-domain (FDTD) software was used for the simulations. The ridge acted as an inductive stub and reduced the frequency. Note, the frequency shift due to the extra change in length was minimal.
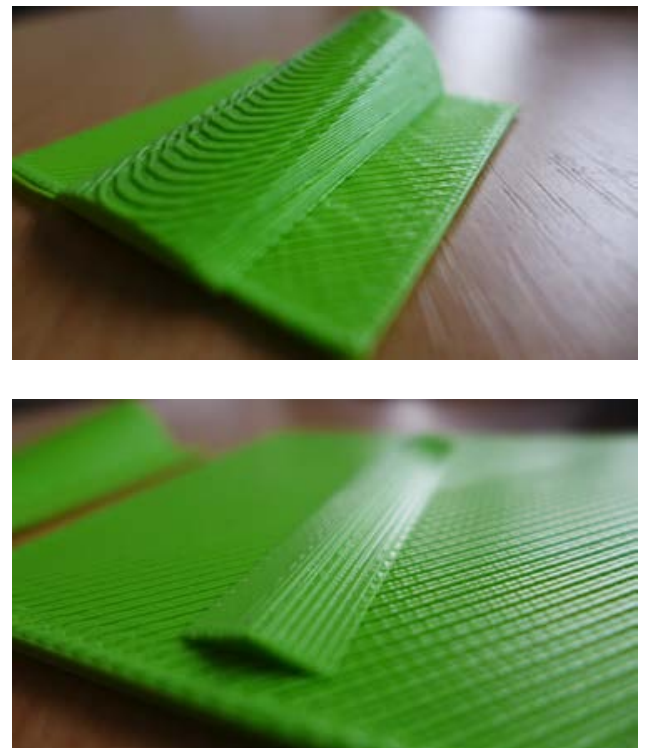

Fig. 4. Examples of non-planar substrates before copper tape is added

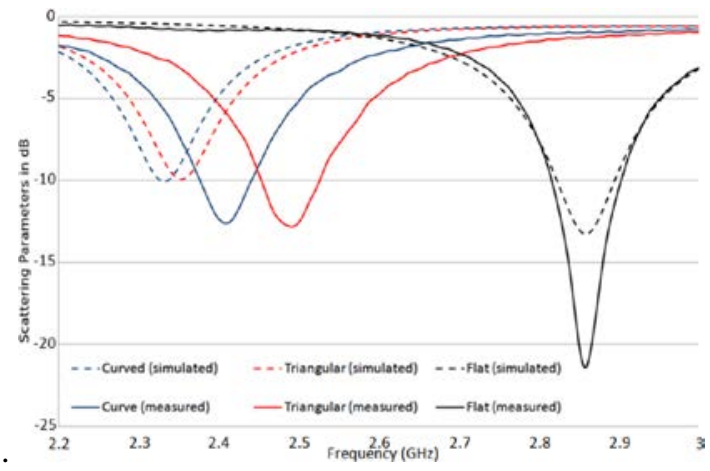

Fig. 5. S11 of patch antennas with ridges at the center

\section{INKJET PRINTED ON-BODY ANTENNAS}

Another fabrication possibility is inkjet printing. This has the advantages of not needing a mask and has a high printing resolution. However, the thickness of the conductor is typically limited to approximately one micron. This means that it is difficult to print on textiles that are absorbent and have a high degree of surface roughness compared to the metallization thickness. The conductivity of the ink is typically around $1 \mathrm{MS} / \mathrm{m}$. It is therefore difficult to use inkjet printing at low frequencies and achieve reasonable efficiencies. One way of circumventing the surface roughness problem is to first screen print an interface layer on top of the fabric. This provides a smooth surface to inkjet print antennas [26]-[28].

The textile element of on-body antennas can even be removed and the antennas can be tattooed onto the skin. Inkjet printing can be used to print conducting shapes onto temporary tattoo paper [29]. Slot antenna based RFID tags were designed. The actual shape of the tag can be varied and was designed to represent Loughborough and Kent University logos [30]. The orientation of the fields within the slot meant the tags could be placed in close proximity to the body. Read ranges of approximately $50 \mathrm{~cm}$ were achieved with only a 10 micron separation layer between the body and the tag. 


\section{EMBROIDERED ANTENNAS}

Embroidery is an attractive possibility for wearable electronics. Specialist conducting threads exist that have a polymer core and a silver / nickel outer coating. They are designed for their conductivity and need to be handled with care to avoid breakages. A specialist embroidery machine at Loughborough University, see Fig. 5, allows the tensions and the speeds to be controlled. The conducting antennas can be designed in electromagnetic software and imported directly into the machine.

Advantages of using embroidery include: aesthetics; not needing glue; one manufacturing process and suitability for unique items or mass manufacturing. The thread can be expensive but this is expected to decrease with time. The resolution of the embroidery process is approximately $0.5 \mathrm{~mm}$. This means it is limited in terms of the maximum frequency. The metallization coating is much thinner than the thread diameter. It is also partially composed of nickel to achieve the adhesion and hence the conductivity is lower than copper. Therefore the frequency range is limited by the skin depth at the lower frequencies and the achievable resolution at higher frequencies.

Published papers on embroidered antennas include [31][41]. The stitch type and direction are important. It was found that the current prefers to travel along the thread rather than jump from thread to adjacent thread. Therefore, the stitch direction should be parallel to the direction of current flow to achieve the highest efficiency. Patch antennas are examples of two dimensional shapes and the current spreads across the surface in two directions. Therefore patch antennas are not ideal candidates for embroidery. Linear antennas such as spirals or fractal antennas are good candidates for embroidery in terms of optimizing the performance and minimizing the length (and cost) of thread required.

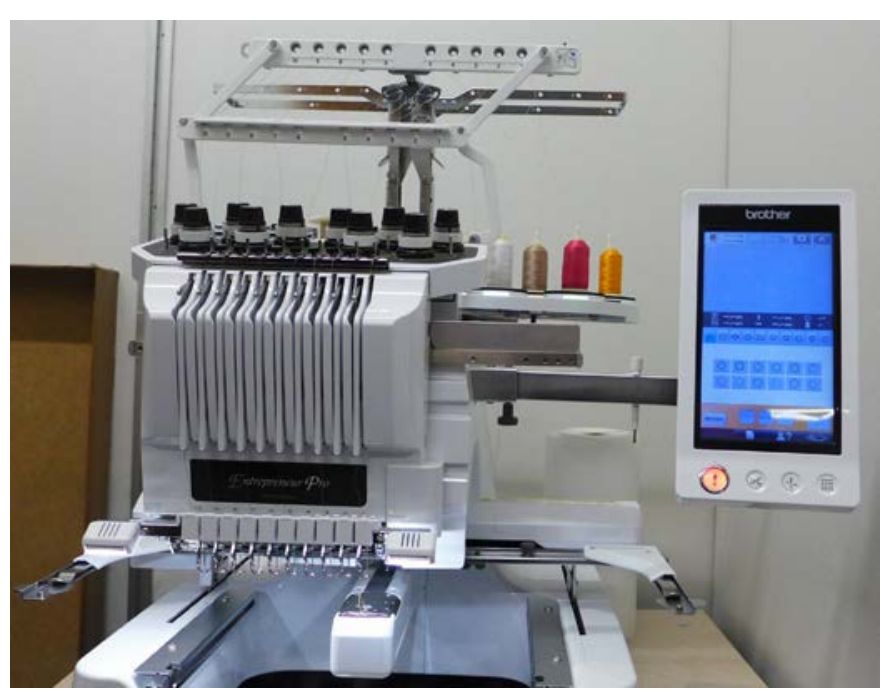

Fig. 6. Digital embroidery machine at Loughborough University

\section{CONCLUSIONS}

This paper has summarized some of the manufacturing techniques used for wearable antennas. 3D Printing offers many new degrees of freedom in terms of shape and dielectric properties. The way the current flows on the embroidered threads naturally lends itself to linear spiral, meandered or fractal antennas.

\section{REFERENCES}

1] J. Brandt, "50 billion connected IoT devices by 2020," SmartGridNews, 2015.2 [Online]. http://www.smartgridnews.com/story/50-billion-connected-iotdevices-2020/2015-04-21

2] D. Evans, "Beyond Things: The Internet of Everything Takes Connections to the Power of Fouro Title,” Cisco Blog, 2013. [Online]. Available: http://blogs.cisco.com/ioe/beyond-things-theinternet-of-everything-takes-connections-to-the-power-of-four.

[3] E. F. Stetter and J. R. Stetter, "The Role of Chemical Sensors in the Trillion Sensor Universe," Sensors Online, 2015. [Online]. Available: $\quad$ http://www.sensorsmag.com/chemical-gas/rolechemical-sensors-trillion-sensor-universe-17488.

4] A. Tsolis, W. G. Whittow, A. A. Alexandridis, and J. C. Vardaxoglou, "Embroidery and related manufacturing techniques for wearable antennas: Challenges and opportunities,” Electronics, vol. 3, no. 2, pp. 314-338, 2014.

[5] A. Cihangir, W. G. Whittow, C. J. Panagamuwa, F. Ferrero, G. Jacquemod, F. Gianesello, and C. Luxey, "Feasibility study of 4G cellular antennas for eyewear communicating devices,” IEEE Antennas Wirel. Propag. Lett., vol. 12, no. DOI: 10.1109/LAWP.2013.2287204, pp. 1704 - 1707, 2013.

[6] N. H. M. Rais, P. J. Soh, F. Malek, S. Ahmad, N. B. M. Hashim, and P. S. Hall, "A Review of Wearable Antenna," in Loughborough Antennas \& Propagation Conference (LAPC), 2009, no. November, pp. 225-228.

[7] J. C. G. Matthews, B. P. Pirollo, A. J. Tyler, and G. Pettitt, "Wideband Body Wearable Antennas,” in Wideband, Multiband Antennas and Arrays for Defence or Civil Applications, 2008 Institution of Engineering and Technology Seminar on, 2008, pp. 111-128.

Z. Shaozhen and R. Langley, "Dual-Band Wearable Textile Antenna on an EBG Substrate," Antennas Propagation, IEEE Trans., vol. 57, no. 4, pp. 926-935, 2009.

P. Salonen, Y. Rahmat-Samii, H. Hurme, and M. Kivikoski, "Dualband wearable textile antenna,” in IEEE Antennas and propagation society international symposium, 2004, pp. 463-466.

T. Kellomaki, J. Virkki, S. Merilampi, and L. Ukkonen, “Towards washable wearable antennas: a comparison of coating materials for screen-printed textile-based UHF RFID tags," Int. J. Antennas Propag., vol. 2012, pp. 1-11, 2012.

Y. Ouyang and W. J. Chappell, "High Frequency Properties of Electro-Textiles for Wearable Antenna Applications,” Antennas Propagation, IEEE Trans., vol. 56, no. 2, pp. 381-389, 2008.

B. Sanz-Izquierdo, F. Huang, and J. C. Batchelor, "Small size wearable button antenna," in First European Conference on Antennas and Propagation (EuCAP), 2006, pp. 1-4.

T. Tuovinen, M. Berg, W. G. Whittow, and E. Salonen, "Impact of Feeding Position on the Performance and Characteristics of Small Wearable On-Ground Antennas,” Prog. Electromagn. Res. C, vol. 57, pp. 53-60, 2015.

C. Hertleer, a. Van Laere, H. Rogier, and L. Van Langenhove, "Influence of Relative Humidity on Textile Antenna Performance," Text. Res. J., vol. 80, no. 2, pp. 177-183, Sep. 2009.

B. Sanz-Izquierdo, J. C. Batchelor, and M. I. Sobhy, "Button antenna on textiles for wireless local area network on body applications," Microwaves, Antennas Propagation, IET, vol. 4, no. 11, pp. 1980-1987, 2010. 

Wireless Communications. London, UK: Artech House, 2012.

[17] W. G. Scanlon and N. E. Evans, "Numerical analysis of bodyworn UHF antenna systems," Electron. Commun. Eng. J., vol. 13, no. 2, pp. 53-64, 2001.

[18] W. G. Whittow and R. M. Edwards, "Applications of a genetic algorithm for identification of maxima in specific absorption rates in the human eye close to perfectly conducting spectacles," IEE Proc. Sci. Meas. Technol., vol. 152, no. 3, pp. 89-96, 2005.

[19] S. Zhang, C. C. Njoku, W. G. Whittow, and J. C. Vardaxoglou, "Novel 3D Printed Synthetic Dielectric Substrates," Microw. Opt. Technol. Lett., vol. 57, no. 10, pp. 2344-2346, 2015.

[20] C. C. Njoku, W. G. Whittow, and J. C. Vardaxoglou, "Simulation Methodology for Synthesis of Antenna Substrates with Micro-scale Inclusions," IEEE Trans Antennas Propag., vol. 60, no. 5, pp. 2194-2202, 2012.

[21] C. C. Njoku, W. G. Whittow, and Y. C. Vardaxoglou, "Effective permittivity of heterogeneous substrates with cubes in a 3D lattice," IEEE Antennas Wirel. Propag. Lett. (Special Issue Metamaterials), vol. 10, pp. 1480-1483, 2011.

[22] J. Krupka, W. Gwarek, N. Kwietniewski, and J. G. Hartnett, "Measurements of Planar Metal - Dielectric Structures Using SplitPost Dielectric Resonators," IEEE Trans. Microw. Theory Tech., vol. 58, no. 12, pp. 3511-3518, 2010.

[23] W. G. Whittow, S. S. Bukhari, L. A. Jones, and I. L. Morrow, "Applications and Future Prospects for Microstrip Antennas using Heterogeneous and Complex 3-D Geometry Substrates,” Prog. Electromagn. Res., vol. 144, pp. 271-280, 2014.

[24] S. S. Bukhari, W. G. Whittow, J. Joubert, and J. C. Vardaxoglou, "Heterogeneous Substrates for Improving the Efficiency and Bandwidth of a Flexible 3D-Printed Microstrip Antenna," J. Eng., vol. In Press, 2015.

[25] P. S. Grant, F. Castles, Q. Lei, Y. Wang, J. M. Janurudin, D. Isakov, S. Speller, C. Dancer, and C. R. Grovenor, "Manufacture of electrical and magnetic graded and anisotropic materials for nove manipulations of microwaves," Philos. Trans. A, vol. 373, no. 2049, p. 20140353, 2015.

[26] W. G. Whittow, A. Chauraya, J. C. Vardaxoglou, L. Yi, R. Torah, K. Yang, S. Beeby, and J. Tudor, "Inkjet Printed Microstrip Patch Antennas Realised on Textile for Wearable Applications," IEEE Antennas Wirel. Propag. Lett., vol. 13, pp. 71-74, 2014.

[27] W. G. Whittow, L. Yi, R. Torah, K. Yang, S. Beeby, and J. Tudor, "Printed frequency selective surfaces on textiles," Electonics Lett., vol. 50, no. 13, pp. 916-917, 2014.

[28] A. Chauraya, W. G. Whittow, J. C. Vardaxoglou, L. Yi, R. Torah, K. Yang, S. Beeby, and J. Tudor, "Inkjet Printed Dipole Antennas on Textiles for Wearable Communications," IET Microwaves, Antennas Propag., vol. 7, no. 9, pp. 760 - 767, 2013.

[29] V. Sanchez-Romaguera, M. A. Zia, D. Oyeka, S. Barbosa, J. S. R. Wheeler, J. C. Batchelor, E. A. Parker, and S. G. Yeates, “Towards inkjet-printed low cost passive UHF RFID skin mounted tattoo paper tags based on silver nanoparticle inks," R. Soc. Chem. J. Mater. Chem. C, vol. 1, pp. 6395-6402, 2013.

[30] J. Tribe, D. Oyeka, J. Batchelor, N. Kaur, D. Segura-Velandia, A. West, R. Kay, K. Vega, and W. G. Whittow, "Tattoo Antenna Temporary Transfers Operating On-Skin (TATTOOS),” in 17th International Conference on Human-Computer Interaction, 2015, pp. 1-12.

[31] K. Koski, E. Moradi, A. A. Babar, T. Björninen, L. Sydänheimo, and L. Ukkonen, "Durability of Embroidered Antennas in Wireless Body-Centric Healthcare Applications," in European Conference on Antennas \& Propagation (EuCAP), 2013, pp. 557-561.

[32] R. D. Seager, S. Zhang, A. Chauraya, W. G. Whittow, J. C. Vardaxoglou, T. Acti, and T. Dias, "Effect of the Fabrication Parameters on the Performance of Embroidered Antennas," IET Microwaves, Antennas Propag., vol. 7, no. 14, pp. 1174-1181, 2013.

[33] E. Moradi, T. Björninen, L. Ukkonen, and Y. Rahmat-samii, "Effects of Sewing Pattern on the Performance of Embroidered Dipole-Type RFID Tag Antennas,” IEEE Antennas Wirel. Propag. Lett., vol. 11, pp. 1482-1485, 2012.

[34] J. Choi, Y. Kim, K. Lee, and Y. Chung, "Various Wearable Embroidery RFID Tag Antenna Using Electro-Thread,” in IEEE Antennas and Propagation Society International Symposium (AP-S 2008), 2008.

[35] T. Acti, A. Chauraya, S. Zhang, W. G. Whittow, R. Seager, J. C Vardaxoglou, and T. Dias, "Embroidered Wire Dipole Antennas Using Novel Copper Yarns,” IEEE Antennas Propag. Wirel. Lett., vol. 14, pp. 638-641, 2015.

[36] Z. Wang, L. Zhang, Y. Bayram, and J. L. Volakis, "Embroidered Conductive Fibers on Polymer Composite for Conformal Antennas,” IEEE Trans Antennas Propag., vol. 60, no. 9, pp. 41414147, 2012.

[37] S. Zhang, A. Chauraya, W. Whittow, R. D. Seager, T. Acti, T. Dias, and J. C. Vardaxoglou, "Embroidered Wearable Antennas Using Conductive Threads with Different Stitch Spacings," in Loughborough Antennas \& Propagation Conference (LAPC), 2012.

[38] J. Roh, Y. Chi, J. Lee, Y. Tak, S. Nam, and T. J. Kang, "Embroidered Wearable Multiresonant Folded Dipole Antenna for FM Reception,” Antennas Wirel. Propag. Lett. IEEE, vol. 9, pp. 803-806, 2010.

[39] T. Maleszka and P. Kabacik, "Bandwidth properties of embroidered loop antenna for wearable applications," in Wireless Technology Conference (EuWIT), 2010 European, pp. 89-92.

[40] T. Acti, S. Zhang, A. Chauraya, W. Whittow, R. Seager, T. Dias, and Y. Vardaxoglou, "High performance flexible fabric electronics for megahertz frequency communications," in 2011 Loughborough Antennas \& Propagation Conference, 2011, pp. 1-4.

[41] T. Kaufmann and C. Fumeaux, "Wearable Textile Half-Mode Substrate-Integrated Cavity Antenna Using Embroidered Vias,” IEEE Antennas Wirel. Propag. Lett., vol. 12, pp. 805-808, 2013. 